\title{
Early Changes and Predictive Value of Serum Histone H3 Concentration in Urosepsis: A Prospective Observational Study
}

\author{
Xiangcheng Zhan · Ding Liu • Yunze Dong • Yunchen Gao • \\ Xiao Xu · Tiancheng Xie · Hongmin Zhou - Guangchun Wang • \\ Haimin Zhang • Pengfei Wu $\cdot$ Xulin He $\cdot$ Chao Sun • Xudong Yao • \\ Yunfei Xu
}

Received: November 15, 2021 / Accepted: December 16, 2021 / Published online: January 23, 2022

(C) The Author(s) 2022

\section{ABSTRACT}

Introduction: To assess early changes in serum histone $\mathrm{H} 3$ concentration in patients with urosepsis and its predictive ability for the onset of urosepsis.

Methods: A total of 80 patients who underwent percutaneous nephrolithotripsy were enrolled in the study and divided into control and

Supplementary Information The online version contains supplementary material available at https:// doi.org/10.1007/s12325-021-02026-9.

X. Zhan $\cdot$ Y. Dong $\cdot$ Y. Gao $\cdot$ X. Xu $\cdot$ T. Xie .

H. Zhou - G. Wang - H. Zhang - P. Wu .

X. Yao $(\bowtie) \cdot$ Y. Xu $(\bowtie)$

Department of Urology, Shanghai Tenth People's

Hospital, School of Medicine, Tongji University,

Shanghai 200072, China

e-mail: yaoxudong1967@163.com

Y. Xu

e-mail: xuyunfeibb@sina.com

D. Liu

Department of Urology, Shanghai Tenth People's Hospital, Nanjing Medical University, Shanghai 200072, China

X. He

Nursing Department, Shanghai Tenth People's

Hospital, Shanghai 200072, China

C. Sun $(\bowtie)$

The Third People's Hospital of Bengbu, Anhui, China

e-mail: supergale@163.com urosepsis groups based on their postoperative outcomes. Serum histone H3 concentrations were detected using an enzyme-linked immunosorbent assay, blood indexes were tested by automatic blood analyzers, and vital signs data were obtained by monitors and manual measurements. These results were correlated with the incidence of postoperative urosepsis. Repeated measurements and receiver operating characteristic curves were employed to analyze early changes and the predictive value of serum histone $\mathrm{H} 3$ concentration in urosepsis.

Results: Sixteen of the 80 patients (20\%) developed urosepsis after surgery. Our data showed significant intra-group differences in terms of postoperative histone $\mathrm{H} 3$ concentrations $(P<0.0001)$ and variation trends $(P<0.0001)$. Among analyzed blood markers, serum histone $\mathrm{H} 3$ concentrations $3 \mathrm{~h}$ postoperation $\quad[0.825 \quad(95 \%$ confidence interval 0.718-0.931, $\quad P<0.0001 ; \quad$ cut-off $\quad$ value $256.74 \mathrm{ng} / \mathrm{ml}, 93.8 \%$ sensitivity, $67.2 \%$ specificity)] and $6 \mathrm{~h}$ post-operation [0.834 (95\% CI 0.721-0.947, $\quad P<0.0001$, cut-off value $300.875 \mathrm{ng} / \mathrm{ml}$, $68.8 \%$ sensitivity, $87.5 \%$ specificity)] displayed a higher area under the corresponding receiver operating characteristic curves, indicating that these markers had a decent predictive value for postoperative urosepsis.

Conclusion: Our study suggests that serum histone $\mathrm{H} 3$ concentration is a novel predictor of 
postoperative urosepsis in patients undergoing percutaneous nephrolithotripsy. The findings of this study can be validated in a larger cohort.

Clinical

Trial

Number: ChiCTR1800016679.

Keywords: Histone H3; Predictive value; Prospective study; Urosepsis

\section{Key Summary Points}

Urosepsis is a disorder response to urinary tract infection which causes lifethreatening organ dysfunction.

Finding biomarkers for early diagnosis may help identify potential uroseptic patients and improve their prognosis.

Serum histone H3 concentration increases significantly at the early stage of urosepsis.

Serum histone H3 concentration could serve as a predictor of the onset of urosepsis.

\section{INTRODUCTION}

Sepsis has become a leading cause of mortality in hospitalized patients and is characterized by life-threatening organ dysfunction caused by a dysregulated host response to infection $[1,2]$. Urosepsis, as the name implies, is sepsis originating from urinary tract infections (UTIs), and it accounts for $25-30 \%$ of all sepsis cases $[3,4]$. Whether UTIs develop into urosepsis depends on the infection site and the potential for systemic spread. Patients can have an almost harmless UTI transform into severe urosepsis within a short period. Kumar et al. reported that, when sepsis occurs, the survival rate of patients decreases by $8 \%$ for every additional hour of administration of sensitive antibiotics [5]. Therefore, early recognition and intervention in urosepsis are key to improving the prognosis of patients.
Presently, clinical diagnosis of urosepsis mainly relies on the Sequential Organ Failure Assessment (SOFA) score or quickSOFA score, in addition to evidence of infection (such as the presence of microorganisms in blood and urine culture results), which lack timeliness as urosepsis cannot be predicted before clinical symptoms occur [6-8]. Inflammation-related blood markers, including white blood cells (WBCs), C-reactive protein (CRP), and procalcitonin, are limited in specificity for urosepsis [9-11]. Hence, there is a demand to identify novel early biomarkers with sufficient predictive value in urosepsis for diagnosis before clinical deterioration.

Histone H3 is a subtype of histone protein, which has been studied as an inflammatory cytokine for over a decade. Previous studies demonstrated that histone $\mathrm{H} 3$ promotes the occurrence of sepsis by damaging endothelial cells, causing pulmonary dysfunction, and inducing disseminated intravascular coagulation (DIC) [12-17]. At the same time, several clinical trials have also confirmed that serum histone $\mathrm{H} 3$ concentrations are correlated with high risk of DIC and death in septic patients $[18,19]$. Given the promoting effect of histone H3 on urosepsis, we hypothesized that serum histone H3 concentration increases in early stages of urosepsis and could serve as a predictor of the occurrence of urosepsis. To verify this hypothesis, we conducted a prospective observational study to explore the early changes and predictive value of serum histone $\mathrm{H} 3$ in urosepsis patients.

\section{METHODS}

\section{Institutional Review Board and Informed Consent}

This study was conducted using a protocol reviewed and approved by the Shanghai Tenth People's Hospital Ethics Committee (protocol number SHSY-IEC-4.0/19-47/01), and was registered in the Chinese Clinical Trial Registry (ChiCTR1800016679). All eligible patients were contacted by the researchers and were provided with a detailed explanation of the clinical trial. 
Signed informed consent was obtained from all the participants.

\section{Inclusion and Exclusion Criteria}

From June 19 to December 31, 2020, patients admitted to the Department of Urology, Shanghai Tenth People's Hospital, because of kidney stones who subsequently underwent PCNL were considered potential participants for the study. Further inclusion criteria were:

1. Age $>18$ years.

2. Unilateral kidney stones $\geq 2 \mathrm{~cm}$ in diameter for which PCNL surgery was performed, with no significant stone residue considered during the surgery.

3. Negative preoperative urine culture test.

4. No infection foci in other organs or preoperative sepsis.

Patients who were pregnant, transferred from another hospital with unclear medical history, unable to provide informed consent, or objected to participating at any point during the study were excluded.

\section{Measurement Content}

The following measurements were performed for patients:

1. Vital signs: Body temperature was manually measured by infrared thermometer (DT$8806 \mathrm{H}$; CEM, China) which can be accurate to $0.1{ }^{\circ} \mathrm{C}$. Respiratory rate, blood pressure, and heart rate were measured by electrocardiogram monitor (IntelliVue MP50; Philips, USA).

2. Laboratory examination: Blood and urine samples were taken for testing in the Department of Clinical Laboratory within $1 \mathrm{~h}$ of admission. Blood samples were tested using an automatic blood analyzer (XE2100; Sysmex, Japan), urine samples were tested using an automatic urine analyzer (AVE-766; AVE, China), and urine culture was conducted using an automatic microbiological identification and drug sensitivity analysis system (VITEK 2 Compact; Bio Mérieux, France).

3. Serum histone H3 concentration: Blood samples were collected into a serum separator tube and allowed to clot for $2 \mathrm{~h}$ at $25^{\circ} \mathrm{C}$ before centrifugation for $20 \mathrm{~min}$ at approximately $1000 \mathrm{~g}$. Once the serum was separated, the histone $\mathrm{H} 3$ concentration was subsequently measured using a human histone H3 ELISA kit (RJ-14954; RENJIEBIO, China). All the serum samples were tested twice and averaged to obtain a final serum histone $\mathrm{H} 3$ value.

\section{Sample Collection Procedure and Grouping Basis}

Blood and urine samples were collected from each patient on admission to the hospital on an empty stomach or after at least $12 \mathrm{~h}$ fasting. Samples were used for hematological, blood biochemical, serum histone $\mathrm{H} 3$, urine routine, and urine culture tests. All the patients received perisurgical antibiotic prophylaxis according to the European Association of Urology guidelines. Patients underwent preoperative risk assessment, achieved stable blood pressure and blood glucose, no urinary tract infection, with other surgical contraindications excluded, such as tumor in the presumptive access tract area, and fasted $12 \mathrm{~h}$ before the surgery. The same chief surgeon operated a $18 \mathrm{Fr}$ percutaneous nephroscope (8968.041; Wolf, Germany) and performed the standard PCNL procedure for all patients, with a nephrostomy tube indwelled. Patients returned to their wards after waking from anesthesia.

Postoperative blood samples were collected three times at 1,3 , and $6 \mathrm{~h}$ after the operation to determine the serum histone H3 concentration, whereas routine blood tests and blood chemistry tests were performed only once at $3 \mathrm{~h}$ postoperatively because of the patients' condition, owing to ethical and economic reasons (Fig. 1). Grouping was determined based on the definition and criteria of Sepsis-3 and the 2020 European Association of Urology guidelines for urosepsis, which identifies sepsis as an increase in the SOFA score of two or more points or a 


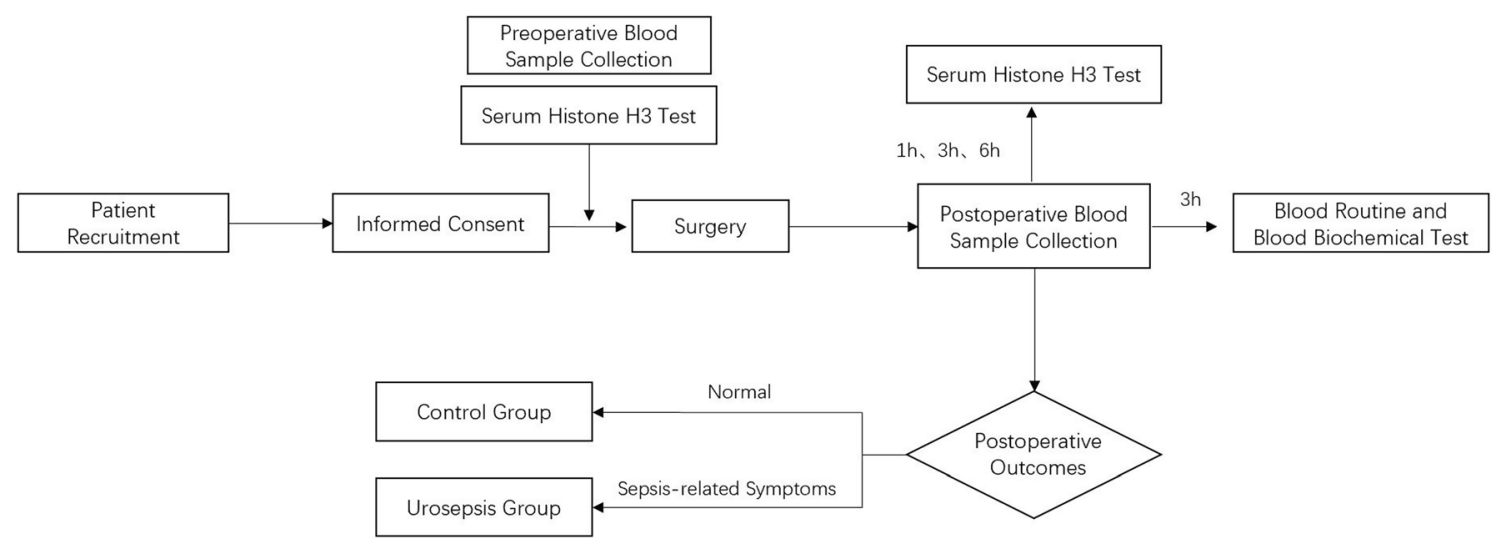

Fig. 1 Sample collection procedure. Enrolled patients' biological samples were collected on admission into the hospital at three postoperative time points. Routine hematological, biochemical, and urine tests were performed

respiratory rate of 22 breaths/min or greater, altered mentation, or systolic blood pressure of $100 \mathrm{mmHg}$ or less for the quickSOFA score [6]. Patients with no postoperative urosepsis were assigned to the control group. As a prospective study, all the samples need to be collected before the clinical outcomes. Therefore, to clarify the time relationship between changes in blood indicators and the onset of urosepsis, we excluded patients who had sepsis before the last blood was obtained $6 \mathrm{~h}$ postoperatively (Fig. 2).

\section{Statistical Analysis}

Statistical analyses were conducted using SPSS v.23.0 (IBM, Armonk, NY, USA) and GraphPad Prism 7 (GraphPad Software, Santiago, CA, USA). Continuous variables are expressed as once at $3 \mathrm{~h}$ postoperative, and serum histone $\mathrm{H} 3$ concentrations were measured three times, at 1,3 , and $6 \mathrm{~h}$, postoperatively

median [interquartile range (IQR)], and categorical variables are expressed as numbers (percentages). The Mann-Whitney $U$ test was used to compare continuous univariate parameters, and the $\chi^{2}$ test was used to compare categorical univariate parameters. Statistical significance was set at $P$ values of $<0.05$. Repeated measurements and the one-way analysis of variance followed by the Dunnett's multiple comparisons test were employed to analyze the differences in serum histone H3 levels over time and between the groups. Receiver operating characteristic (ROC) curves were analyzed to determine the diagnostic value of parameters with statistical significance. Areas under the curve (AUC) were expressed with 95\% confidence intervals (CIs).

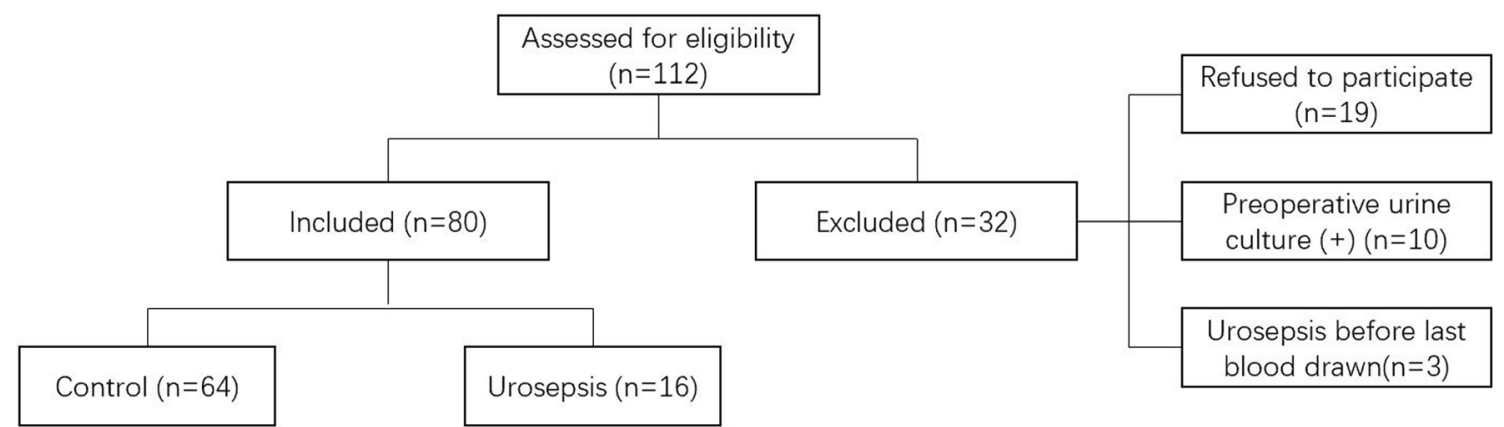

Fig. 2 Flowchart for patients enrolled 


\section{RESULTS}

During the 6-month period, 80 patients who underwent PCNL were enrolled in the study. The average age was 58.36 years (range 24-78 years), and 51 of the enrolled patients were males (64\%). In terms of postoperative outcomes, 64 patients had no infection-related complications after the surgery, while 16 patients developed postoperative urosepsis.

\section{Baseline Characteristics of Patients}

We collected the patients' general information and hematological and urine indices (Table 1). There were no significant differences in age, sex, medical history, or blood test results between the two groups. In the urine tests, the proportion of patients with positive urine leukocyte esterase (LE) test results was higher in the urosepsis group than in the control group (14/ 16 compared to 30/64), and the LE levels were significantly higher in the urosepsis group than in the control group $(P<0.01)$. However, the urinary WBC count was significantly lower in the urosepsis group than in the control group $(P<0.05)$.

\section{Postoperative Laboratory Examination and Vital Sign of Patients}

Postoperative blood and urine samples were collected $3 \mathrm{~h}$ postoperation, and vital signs were constantly monitored with values at each of the postoperative time points displayed in Table 2 . Blood CRP and neutrophil levels were significantly higher $(P<0.05)$, and lymphocyte levels were lower in the urosepsis group than in the control group $(P<0.05)$. The patients' vital signs began to show differences at $3 \mathrm{~h}$ postoperatively; we observed higher body temperatures and respiratory rates in patients with urosepsis $(P<0.05)$; however, no differences were found in the heart rate and blood pressure. A breakdown of the microorganisms isolated from the sepsis patients is included as supplementary material (Table S1).
Trends in Serum Histone H3 concentrations Over Time in the Two Groups

We examined the serum histone H3 concentrations at each time point in the two groups (Fig. 3). Serum histone H3 concentrations in the control group showed a trend of first increasing and then decreasing, with the peak occurring at $1 \mathrm{~h}$ postoperatively. In contrast, in the urosepsis group, the serum histone $\mathrm{H} 3$ concentrations increased continually after the surgery, and the differences in histone $\mathrm{H} 3$ concentrations $6 \mathrm{~h}$ postoperatively compared to histone H3 concentrations before the operation and $1 \mathrm{~h}$ postoperatively were statistically significant $(P<0.0001$ before the operation and $P<0.01$ $1 \mathrm{~h}$ postoperatively).

\section{Comparison of Each Time Point's Serum Histone H3 Concentrations Between the Two Groups.}

We compared the serum histone H3 concentrations at each time point in both groups (Fig. 4). Before the operation, serum histone H3 concentrations in both groups were below $200 \mu \mathrm{g} / \mathrm{ml}$, with no significant differences between them (Fig. 4A). The histone H3 concentrations in both the groups increased by $1 \mathrm{~h}$ postoperatively, but no differences were observed (Fig. 4B). However, differences began to show $3 \mathrm{~h}$ postoperatively where the histone H3 concentrations in the urosepsis group continued to increase and were significantly higher than those in the control group $(P<0.0001)$ (Fig. 4C, D).

\section{Inter-group Differences in Trends in Serum Histone H3 Concentration Over Time}

To better understand inter-group differences in trends in the serum histone $\mathrm{H} 3$ concentration over time, we performed repeated measurements (Table 3). The Mauchly's test of sphericity revealed that the significance of withinsubject effects of histone $\mathrm{H} 3$ concentration was $0.118 \quad(P>0.05)$, which required the 
Table 1 Baseline characteristics of patients

\begin{tabular}{llclll}
\hline Index & Control $(\boldsymbol{n}=\mathbf{6 4})$ & Urosepsis $(\boldsymbol{n}=\mathbf{1 6})$ & $\boldsymbol{U}$ & $\boldsymbol{Z}$ & $\boldsymbol{P}$ \\
\hline General information & & & & & \\
Age (years old) & $58.67(52,70)$ & $57.13(42,71)$ & 503.5 & -0.102 & 0.918 \\
Male $(n, \%)$ & $42(65.6)$ & $9(56.3)$ & 464 & -0.693 & 0.488 \\
DM $(n, \%)$ & $15(23.4)$ & $4(25)$ & & & 0.895 \\
HT $(n, \%)$ & $31(48.4)$ & $8(50)$ & & 0.911
\end{tabular}

Blood

Biochemical index

$$
\text { CRP (mg/l) }
$$

$6.37(0.8,6.39)$

$4.7(0.87,4.5)$

$501.5-0.031$

0.976

Hematological indexes

$\begin{array}{ll}\text { WBC }\left(\times 10^{9} / \mathrm{l}\right) & 6.5(5.47,7.38) \\ \operatorname{RBC}\left(\times 10^{12} / \mathrm{l}\right) & 4.32(3.98,4.65) \\ \mathrm{HB}(\mathrm{g} / \mathrm{l}) & 133.86(122,146) \\ \operatorname{PLT}\left(\times 10^{9} / \mathrm{l}\right) & 227.97(178,268) \\ \text { Neutrophil }\left(\times 10^{9} / \mathrm{l}\right) & 4.18(3.21,4.81) \\ \text { Lymphocyte }\left(\times 10^{9} / \mathrm{l}\right) & 1.73(1.28,1.98) \\ \text { Monocyte }\left(\times 10^{9} / \mathrm{l}\right) & 0.42(0.33,0.47)\end{array}$

Urine

\section{Urine $\mathrm{pH}$}

LE $(n, \%)$

0

$1+$

$2+$

$3+$

Urine protein $(n, \%)$

0

$1+$

$2+$

$\operatorname{BLD}(n, \%)$

0

$1+$

$2+$

$3+$

$4+$
$6.1(6,6.5)$

34 (53.1)

$20(31.3)$

$5(7.8)$

$5(7.8)$

53 (82.8)

8 (12.5)

$3(4.7)$

12 (18.8)

14 (21.9)

$6(9.4)$

$18(28.1)$

14 (21.8)
$7.6(5.9,8.64)$

$4.39(4.05,4.6)$

$134.38(122,146)$

$241.06(208,325)$

$4.8(3.65,5.51)$

$2.11(1.53,2.79)$

$0.43(0.30,0.56)$

$5.91(5,6.5)$

$2(12.5)$

7 (43.75)

3 (18.75)

$4(25)$

0.11

$10(62.5)$

3 (18.75)

3 (18.75)

$1(6.25)$

$6(37.5)$

3 (18.75)

2 (12.5)

$4(25)$ 
Table 1 continued

\begin{tabular}{llclrr}
\hline Index & Control $(\boldsymbol{n}=\mathbf{6 4})$ & Urosepsis $(\boldsymbol{n}=\mathbf{1 6})$ & $\boldsymbol{U}$ & $\boldsymbol{Z}$ & $\boldsymbol{P}$ \\
\hline Urine RBC $(n / \mathrm{HP})$ & $180.55(0.5,39.75)$ & $90.31(4.25,51.75)$ & 504 & -0.097 & 0.686 \\
Urine WBC $(n / \mathrm{HP})$ & $176.09(0,30)$ & $55.38(11.25,48)$ & 330 & -2.233 & $<0.05^{\mathrm{a}}$ \\
Urine epithelia $(n / \mathrm{HP})$ & $2.08(0,2)$ & $4.25(0,2)$ & 483 & -0.404 & 0.686 \\
\hline
\end{tabular}

Patients' general information, blood, and urine laboratory test results are displayed. Blood and urine samples were collected on admission to the hospital. Continuous variables are expressed as median values (IQR), and categorial variables are expressed as numbers (percentages)

$D M$ diabetes, $H T$ hypertension, $C R P$ C-reaction protein, $W B C$ white blood cell, $R B C$ red blood cell, $H B$ hemoglobin, $P L T$ platelet, $L E$ leukocyte esterase

${ }^{a}$ Significant difference using the Mann-Whitney $U$ test

${ }^{\mathrm{b}}$ Significant difference using the $\chi^{2}$ test

Greenhouse-Geisser correction. Further tests of within-subject effects with the Greenhouse-Geisser correction showed significant differences between the groups $(P<0.0001)$, and indicated that patients in the urosepsis group had greater changes in serum histone H3 concentrations over time than those in the control group. The trend graph clearly shows these differences between the groups (Fig. 5).

\section{Diagnostic Capability of Parameters with Significant Differences}

Patients who developed urosepsis had significant differences in several parameters of postoperative blood tests and vital signs, as well as in serum histone $\mathrm{H} 3$ concentrations compared with patients in the control group (Table 2; Figs. 3 and 4). To further explore the diagnostic capability of each parameter, we generated the ROC curves.

Vital signs, postoperative temperature, and respiratory rate at $3 \mathrm{~h}$ and $6 \mathrm{~h}$ postoperatively, were included in one ROC curve. The AUC values were 0.716 for temperature $3 \mathrm{~h}$ postoperatively (95\% CI $0.546-0.886, P=0.087), 0.658$ for respiratory rate $3 \mathrm{~h}$ postoperatively (95\% CI $0.473-0.842, P=0.052), 0.670$ for temperature $6 \mathrm{~h}$ postoperatively $(95 \%$ CI $0.483-0.858$, $P=0.036$ ), and 0.693 for respiratory rate $6 \mathrm{~h}$ postoperatively $\quad(95 \%$ CI $0.529-0.856$, $P=0.018$ ) (Fig. 6).
Blood CRP levels, WBC counts, neutrophil counts, and lymphocyte levels, which were measured only once $3 \mathrm{~h}$ postoperatively, have been included in another ROC curve. The AUC values were 0.758 for CRP levels $(95 \%$ CI $0.633-0.883, P<0.001$, cut-off value $1.995 \mathrm{mg} /$ $1,81.3 \%$ sensitivity, $64.1 \%$ specificity), 0.713 for leukocyte counts (95\% CI $0.570-0.857$, $P=0.009$, cut-off value $8.73 \times 10^{9} / 1,56.3 \%$ sensitivity, $79.7 \%$ specificity), 0.775 for neutrophil levels $(95 \%$ CI $0.647-0.904, P<0.001$, cut-off value $5.92 \times 10^{9} / \mathrm{L}, \quad 75 \%$ sensitivity, $73.4 \%$ specificity), and 0.747 for lymphocyte counts $(95 \%$ CI $0.617-0.876, P=0.002$, cut-off value $1.115 \times 10^{9} / \mathrm{L}, \quad 75 \%$ sensitivity, $68.7 \%$ specificity) (Fig. 7).

Postoperative serum histone H3 concentrations were also assessed using the ROC curve. The AUC for histone H3 concentration at each time point was $0.4551 \mathrm{~h}$ postoperatively (95\% CI $0.253-0.657, P=0.580), 0.8253$ h postoperatively (95\% CI $0.718-0.931, P<0.0001$, cut-off value $256.74 \mu \mathrm{g} / \mathrm{ml}, 93.8 \%$ sensitivity, $67.2 \%$ specificity), and $0.8346 \mathrm{~h}$ postoperatively $(95 \%$ CI $0.721-0.947, \quad P<0.0001$, cut-off value $300.875 \mu \mathrm{g} / \mathrm{ml}$, $68.8 \%$ sensitivity, $87.5 \%$ specificity) (Fig. 8). Based on these ROC curves, after abandoning parameters whose AUC values were below 0.7 and $P>0.05$, the diagnostic capability of each parameter from most efficient to least efficient was histone $\mathrm{H} 3$ concentrations $6 \mathrm{~h}$ postoperatively $(0.834)$, histone $\mathrm{H} 3$ concentrations $3 \mathrm{~h}$ postoperatively (0.825), 
Table 2 Postoperative indexes of patients

\begin{tabular}{llllll}
\hline Index & Control $(n=64)$ & Urosepsis $(n=16)$ & $U$ & $Z$ & $P$ \\
\hline
\end{tabular}

Blood

Biochemical index

$$
\text { CRP (mg/l) }
$$

Hematological indexes

$$
\begin{aligned}
& \text { WBC }\left(\times 10^{9} / \mathrm{l}\right) \\
& \operatorname{RBC}\left(\times 10^{12} / \mathrm{l}\right) \\
& \operatorname{HB}(\mathrm{g} / \mathrm{l}) \\
& \operatorname{PLT}\left(\times 10^{9} / \mathrm{l}\right) \\
& \text { Neutrophil }\left(\times 10^{9} / \mathrm{l}\right) \\
& \text { Lymphocyte }\left(\times 10^{9} / \mathrm{l}\right) \\
& \text { Monocyte }\left(\times 10^{9} / \mathrm{l}\right)
\end{aligned}
$$$$
7.6(0.8,3.54)
$$$$
28.45(2,54.02)
$$$$
248
$$$$
-3.181
$$$$
<0.01^{\mathrm{a}}
$$

$6.97(4.87,8.26)$
$4.1(3.81,4.57)$
$128.61(115,139)$
$199.56(157,232)$
$5.09(2.96,6.34)$
$1.42(1.03,1.83)$
$0.32(0.14,0.4)$

$9.93(6.31,12.92)$

$4.08(3.76,4.44)$

$122.94(108,142)$

192.81 (157.75, 218.25)

$8.58(5.04,10.98)$

$0.89(0.46,1.21)$

$0.92(0.06,0.53)$

$1 \mathrm{~h} \mathrm{~T}\left({ }^{\circ} \mathrm{C}\right)$

$1 \mathrm{~h} \mathrm{RR}(\mathrm{r} / \mathrm{min})$

$1 \mathrm{~h} \mathrm{HR}(\mathrm{b} / \mathrm{min})$

$1 \mathrm{~h}$ Systolic pressure $(\mathrm{mmHg})$

$1 \mathrm{~h}$ Diastolic pressure $(\mathrm{mmHg})$

$3 \mathrm{~h} \mathrm{~T}\left({ }^{\circ} \mathrm{C}\right)$

3 h RR (r/min)

$3 \mathrm{~h} \mathrm{HR}(\mathrm{b} / \mathrm{min})$

$3 \mathrm{~h}$ Systolic pressure $(\mathrm{mmHg})$

$3 \mathrm{~h}$ Diastolic pressure $(\mathrm{mmHg})$

$6 \mathrm{~h} \mathrm{~T}\left({ }^{\circ} \mathrm{C}\right)$

$6 \mathrm{~h} \mathrm{RR}(\mathrm{r} / \mathrm{min})$

$6 \mathrm{~h} \mathrm{HR}(\mathrm{b} / \mathrm{min})$

$6 \mathrm{~h}$ Systolic pressure $(\mathrm{mmHg})$

$6 \mathrm{~h}$ Diastolic pressure $(\mathrm{mmHg})$

$\begin{array}{ll}18.34(18,20) & 18.69(18,20) \\ 79.73(79,82) & 83(80,84) \\ 135.56(129,141) & 133.38(128,135) \\ 81.31(77,85) & 79.94(75,84) \\ 36.85(36.6,37) & 37.68(36.6,38.5) \\ 18.64(18,20) & 26.31(18,26) \\ 80.89(79,82) & 83.31(79,98) \\ 134(128,138) & 134.06(130,140) \\ 79.72(76,82) & 78.06(71,82) \\ 37.03(36.6,37.5) & 37.61(36.7,38.5) \\ 18.64(18,20) & 20.81(18,24) \\ 80.31(80,82) & 85.69(80,89) \\ 129.48(122,135) & 123.81(108,133) \\ 79.17(74,80) & 74.06(70,82)\end{array}$

$37.15(36.5,37.3)$

$440.5-0.879$

$433-1.196$

$421.5-1.167$

$426.5-1.032$

$484-0.339$

$291-2.688$

$<0.05^{\mathrm{a}}$

350.5

498

467

451

337.5

314.5

$-2.144$

$<0.05^{\mathrm{a}}$

$-0.171$

0.864

$-0.544$

0.586

0.46

$-0.739$

$<0.05^{\mathrm{a}}$

412

393

$-2.117$

$-2.64$

$<0.05^{\mathrm{a}}$

0.221

$422.5-1.083$

0.151

0.279

Patients' postoperative laboratory test results and vital signs. Blood and urine samples were collected $3 \mathrm{~h}$ after the operation, and vital signs were constantly monitored, with values at each of the postoperative time points displayed. Continuous variables are expressed as median values (IQR), and categorial variables are expressed as numbers (percentages)

$T$ temperature, $R R$ respiratory rate, $H R$ heart rate

${ }^{a}$ Significant difference using the Mann-Whitney $U$ test 
A

Control

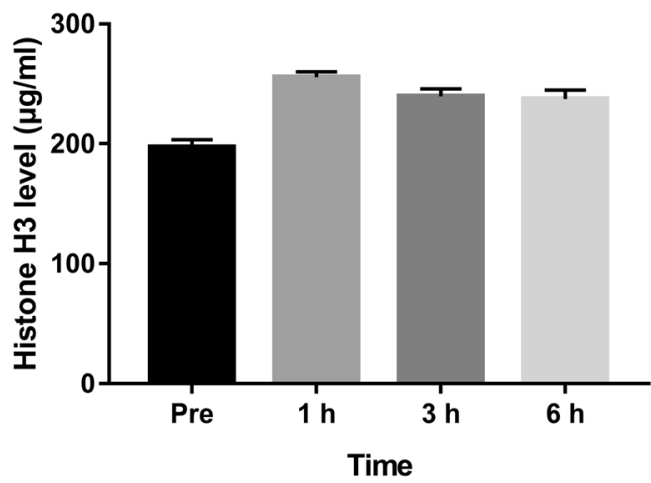

Fig. 3 Trends in serum histone $\mathrm{H} 3$ concentrations over time in the two groups. Blood samples were collected at different time points before and after the surgery. A Serum histone $\mathrm{H} 3$ concentrations at each time point in the control group. Mean \pm SEM, $n=64$, no significant
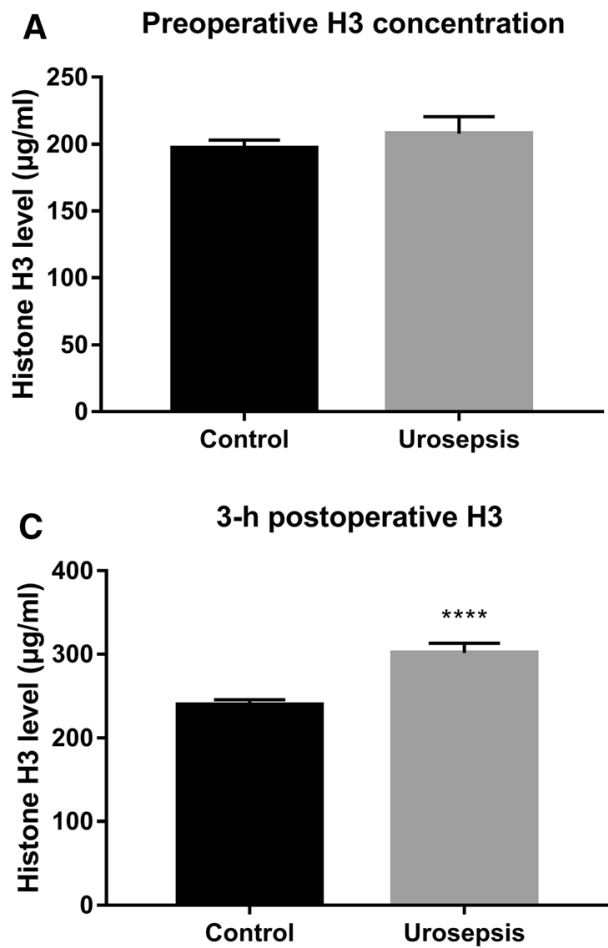

Fig. 4 Comparison of serum histone H3 levels at each time point between the two groups. Blood samples were collected at different time points before and after the surgery. A-D Each groups' serum histone H3
B Urosepsis

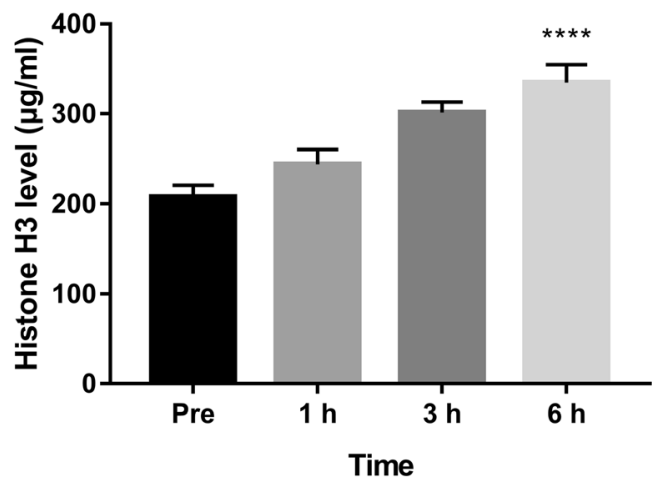

difference was found. B Serum histone H3 concentrations at each time point in the urosepsis group. Mean \pm SEM, $n=16,{ }^{* * *} P<0.0001$ compared to preoperative concentrations. SEM standard error of mean

B 1-h postoperative $\mathrm{H} 3$

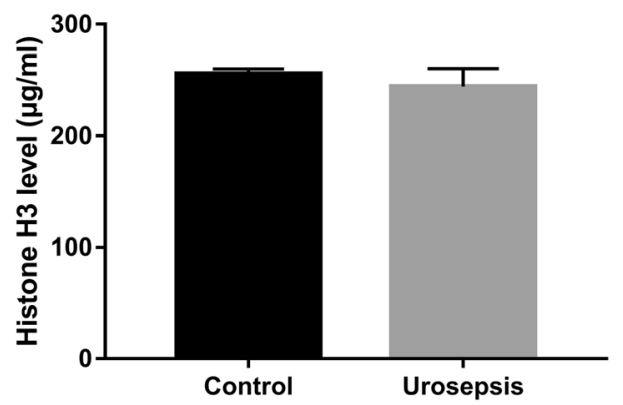

D

6-h postoperative H3

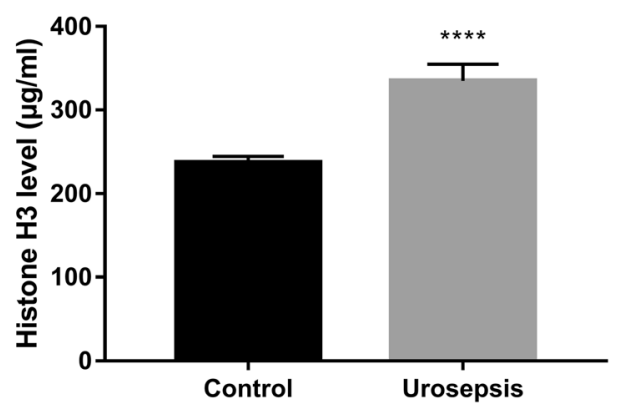

concentrations at each time point. Mean \pm SEM, control $n=64$, urosepsis $n=16,{ }^{* * * *} P<0.0001$, when compared to the control group at $3 \mathrm{~h}$ and $6 \mathrm{~h}$ postoperatively 
Table 3 Repeated measurement of inter-group differences of histone H3

\begin{tabular}{llcc}
\hline Within subjects effects & Mauchly's $\boldsymbol{W}$ & Approx. $\boldsymbol{\chi}^{\mathbf{2}}$ & $\boldsymbol{P}$ \\
\hline Mauchly's test of sphericity & 0.892 & 8.793 & 0.118 \\
Histone H3 & Correction & F & $\boldsymbol{P}$ \\
\hline Source & & & \\
\hline Tests of within-subjects effects & Greenhouse-Geisser & 38.01 & $<0.0001^{\text {a }}$ \\
Histone H3 & Greenhouse-Geisser & 17.436 & $<0.0001^{\text {b }}$ \\
Histone H3 $\times$ group & &
\end{tabular}

Repeated measurement of inter-group differences of histone H3. Results of Mauchly's test of sphericity and tests of withinsubject effects with Greenhouse-Geisser correction are displayed

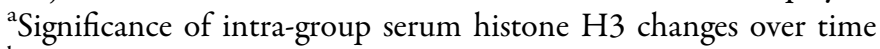
${ }^{\mathrm{b}}$ Significance of inter-group serum histone $\mathrm{H} 3$ changes over time

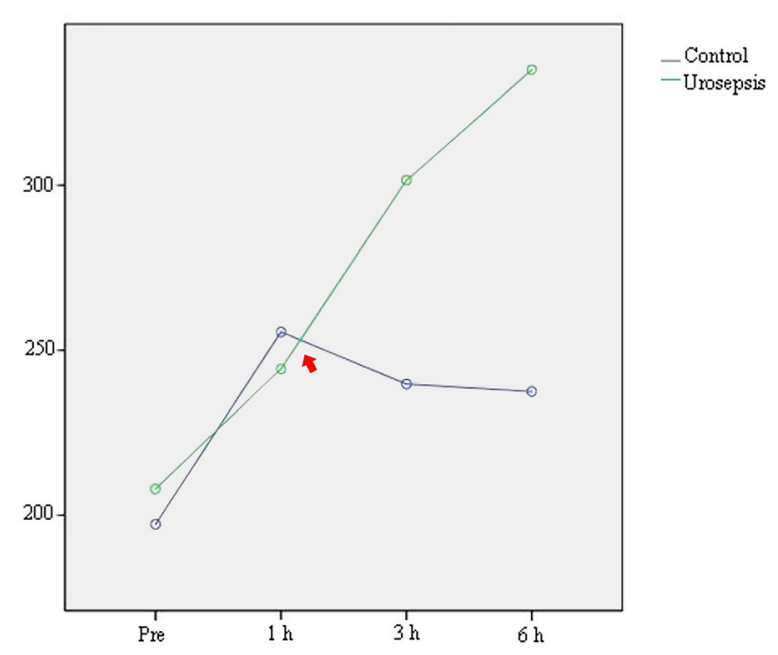

Fig. 5 Trend graph of serum histone $\mathrm{H} 3$ concentrations over time in the two groups. The $x$-axis represents time of measurement, and the $y$-axis represents histone $\mathrm{H} 3$ level $(\mu \mathrm{g} / \mathrm{ml})$. Blue line changing histone $\mathrm{H} 3$ concentrations in the control group over time; green line changing histone $\mathrm{H} 3$ concentrations in the urosepsis group over time; red arrow indicates the point at which a significant trend difference can be observed between the groups

neutrophil counts (0.775), CRP levels (0.758), lymphocyte counts (0.747), and leukocyte counts (0.713).

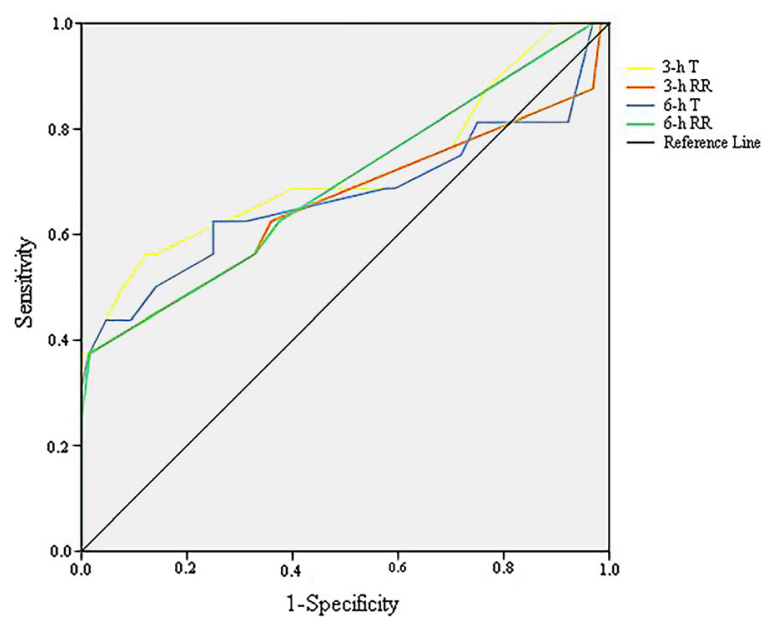

Fig. 6 ROC for postoperative vital signs. AUC values for temperature and respiratory rate $3 \mathrm{~h}$ postoperatively were 0.716 and 0.658 , respectively, and those for temperature and respiratory rate 6 h operatively were 0.670 and 0.693 , respectively

\section{DISCUSSION}

Urosepsis has long been a challenging problem in clinical urology. Seeking biomarkers that can be used to predict the occurrence of urosepsis may contribute to the early diagnosis of urosepsis and improve the prognosis of septic patients. Based on previous studies, we supposed that serum histone $\mathrm{H} 3$ is the biomarker 


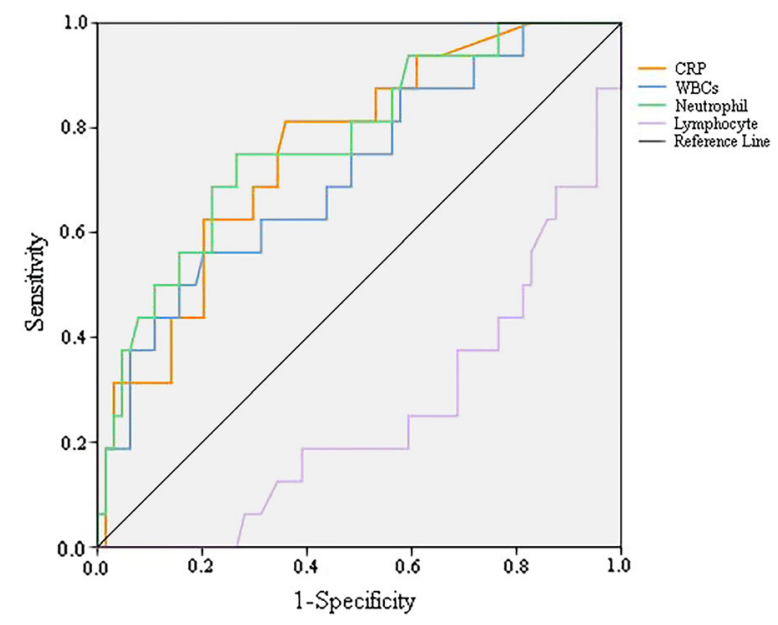

Fig. 7 ROC for postoperative blood indexes. AUC values for blood CRP, leukocyte, neutrophil, and lymphocyte were $0.758,0.713,0.775$, and 0.747 , respectively

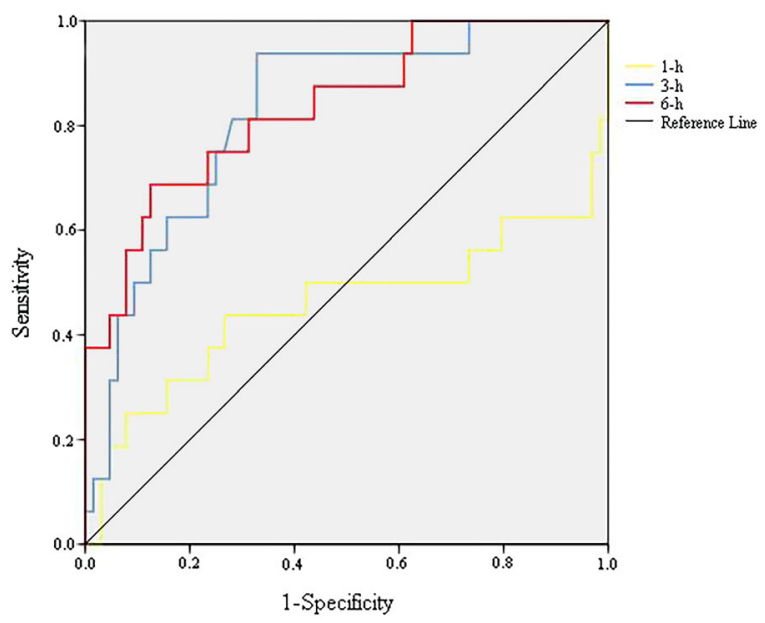

Fig. 8 ROC of postoperative serum histone H3. AUC values for serum histone $\mathrm{H} 3$ concentration $1 \mathrm{~h}, 3 \mathrm{~h}$, and $6 \mathrm{~h}$ postoperatively were $0.455,0.825$, and 0.834 , respectively

with such potential. We enrolled 80 patients who underwent PCNL procedure and grouped them according to their post-operative outcomes, serum histone $\mathrm{H} 3$ concentrations were compared with established blood markers and clinical manifestations in terms of diagnostic efficiency. As a result, we demonstrated that serum histone $\mathrm{H} 3$ concentrations can be an adequate predictor for the onset of urosepsis.

Since the revision of the international consensus of Sepsis-3, the diagnosis rate of sepsis has greatly improved, revealing sepsis to be among the most serious complications in patients after PCNL, with an incidence ranging from 3.5 to $35.05 \%$ [20-24]. The release of kidney stone-colonizing bacteria and other bacterial endotoxins during surgery into the circulation system coupled with elevated renal pelvis pressure is believed to be the main cause of postoperative infection and urosepsis $[25,26]$. Therefore, kidney stones themselves are a potential source of infection, which may explain why some of the patients' urine culture results turned positive after surgery, and they subsequently developed urosepsis.

A patient's vital signs are often the first indication of postoperative outcomes, even before the ability to establish a urosepsis diagnosis. We found differences in body temperature and respiratory rate 3 and $6 \mathrm{~h}$ postoperatively; however, the results of the ROC analysis showed that either their AUC values were less than 0.7 or the results were not statistically significant, implying that they have limited diagnostic value for the occurrence of postoperative urosepsis (Fig. 6). Nevertheless, it is undeniable that vital signs remain a fundamental basis for diagnosing sepsis and septic shock.

Extracellular histone $\mathrm{H} 3$ is mainly phagocytosed and cleared by monocytes and macrophages $[27,28]$. However, when a patient is under severe trauma or experiences inflammation or other pathological conditions, large amounts of extracellular histone $\mathrm{H} 3$ are released into blood circulation from necrotic cells and neutrophil extracellular traps, which subsequently exerts its damage-associated molecular pattern effects by activating inflammatory pathways; thus, damaging the vascular endothelium, and triggering platelet aggregation and clotting [14, 29-34]. Additionally, extracellular histone $\mathrm{H} 3$ can significantly impair the clearing ability of macrophages [35], thus forming a vicious cycle of continued accumulation of extracellular H3 and progression of inflammatory processes in the body, which considerably contribute to the occurrence of sepsis. This may explain the transient increase in histone $\mathrm{H} 3$ concentrations in the control group within a short period of time after 
surgery and the differences in the trend in serum histone H3 concentrations over time between the urosepsis and control groups. In fact, multiple studies have reported elevated histone H3 concentrations in sepsis patients $[18,19,36,37]$. Additionally, it is worth noting that our research shows that serum histone $\mathrm{H} 3$ concentrations at 3 and $6 \mathrm{~h}$ postoperatively had a better predictive efficiency for the occurrence of urosepsis than other blood indicators (AUC, 0.825 and 0.834 , respectively). Therefore, the clinical application of postoperative serum histone H3 concentration detection may help in the early diagnosis of urosepsis and improve patient prognosis.

This study had several limitations. First, this was a single-center trial with relatively few enrolled cases, and true clinical promotion and application requires larger-scale experimental validation. Second, as this was a prospective study with ethical limitations, our monitoring of serum histone H3 concentrations only lasted until $6 \mathrm{~h}$ after the surgery; therefore, we could not detect subsequent changes to investigate the relationship between histone $\mathrm{H} 3$ concentrations and urosepsis severity. We expect to explore the correlations among histone H3 concentrations, SOFA scores, and patient prognosis in further studies.

In conclusion, serum histone H3 concentrations and its early postoperative changes in patients with postoperative urosepsis were significantly different from those in patients without postoperative urosepsis. Therefore, serum histone $\mathrm{H} 3$ concentrations may serve as an indicator for predicting the occurrence of postoperative urosepsis, which will contribute to the early diagnosis of urosepsis, in order to help recognize potential patients and improve their prognosis; however, further larger-scale studies are required to validate these results.

\section{ACKNOWLEDGEMENTS}

The authors would like to thank all the participants, and the nurses of Department of Urology, Shanghai Tenth People's Hospital, for their hard work in patient care.
Funding. The study was funded by the Research Project of Shanghai Municipal Health Commission (No. 201940105, Shanghai, China) and Research Project of Science and Technology Commission of Shanghai Municipality (No. 19140905402, Shanghai, China). The journal's Rapid Service and Open Access fees was funded by the authors.

Authorship. All named authors meet the International Committee of Medical Journal Editors (ICMJE) criteria for authorship for this article, take responsibility for the integrity of the work, and have given their approval for this version to be published.

Author Contributions. Conceptualization: Yunfei $\mathrm{Xu}$, Xudong Yao, and Chao Sun; Methodology: Ding liu, Yunze Dong, and Yuchen Gao; Formal analysis and investigation: Xiangcheng Zhan, Guangchun Wang, Haimin Zhang, Pengfei Wu, and Xulin He; Writing and original draft preparation: Xiangcheng Zhan; Writing, review, and editing: Tiancheng Xie, $\mathrm{XiaO} \mathrm{Xu}$, and Hongmin Zhou; Funding acquisition: Yunfei Xu; Resources: Xudong Yao, Chao Sun, and Xiangcheng Zhan; Supervision: Yunfei, $\mathrm{Xu}$.

Disclosures. Xiangcheng Zhan, Ding Liu, Yunze Dong, Yunchen Gao, Xiao Xu, Tiancheng Xie, Hongmin Zhou, Guangchun Wang, Haimin Zhang, Pengfei Wu, Xulin He, Chao Sun, Xudong Yao and Yunfei Xu declare that they have nothing to disclose.

\section{Compliance with Ethics Guidelines.} Research ethical approval was approved by the Shanghai Tenth People's Hospital Ethics Committee (protocol number SHSY-IEC-4.0/19-47/ $01)$ and was registered in the Chinese Clinical Trial Registry (ChiCTR1800016679).

Data Availability. The datasets generated during and/or analyzed during the current study are available from the corresponding author on reasonable request.

Open Access. This article is licensed under a Creative Commons Attribution- 
NonCommercial 4.0 International License, which permits any non-commercial use, sharing, adaptation, distribution and reproduction in any medium or format, as long as you give appropriate credit to the original author(s) and the source, provide a link to the Creative Commons licence, and indicate if changes were made. The images or other third party material in this article are included in the article's Creative Commons licence, unless indicated otherwise in a credit line to the material. If material is not included in the article's Creative Commons licence and your intended use is not permitted by statutory regulation or exceeds the permitted use, you will need to obtain permission directly from the copyright holder. To view a copy of this licence, visit http:// creativecommons.org/licenses/by-nc/4.0/.

\section{REFERENCES}

1. Howell MD, Davis AM. Management of sepsis and septic shock. JAMA. 2017;317(8):847-8. https://doi. org/10.1001/jama.2017.0131\%JJAMA.

2. Hotchkiss RS, Sherwood ER. Immunology Getting sepsis therapy right. Science. 2015;347(6227): 1201-2. https://doi.org/10.1126/science.aaa8334.

3. Wagenlehner FME, Pilatz A, Weidner W, Naber KG. Urosepsis: overview of the diagnostic and treatment challenges. Microbiol Spectrum. 2015. https://doi. org/10.1128/microbiolspec.UTI-0003-2012.

4. Porat A, Bhutta BS, Kesler S. Urosepsis. StatPearls. Treasure Island: StatPearls Publishing. Copyright (C) 2021, StatPearls Publishing LLC.; 2021.

5. Kumar A, Roberts D, Wood KE, Light B, Parrillo JE, Sharma $S$, et al. Duration of hypotension before initiation of effective antimicrobial therapy is the critical determinant of survival in human septic shock. Crit Care Med. 2006;34(6):1589-96. https:// doi.org/10.1097/01.Ccm.0000217961.75225.E9.

6. Singer M, Deutschman CS, Seymour CW, ShankarHari M, Annane D, Bauer M, et al. The Third International Consensus Definitions for Sepsis and Septic Shock (Sepsis-3). JAMA. 2016;315(8):801-10. https://doi.org/10.1001/jama.2016.0287.

7. Bone RC, Balk RA, Cerra FB, Dellinger RP, Fein AM, Knaus WA, et al. Definitions for sepsis and organ failure and guidelines for the use of innovative therapies in sepsis. The ACCP/SCCM Consensus Conference Committee. American College of Chest Physicians/Society of Critical Care Medicine. Chest. 1992;101(6):1644-55. https://doi.org/10.1378/ chest.101.6.1644.

8. Levy MM, Fink MP, Marshall JC, Abraham E, Angus D, Cook D, et al. 2001 SCCM/ESICM/ACCP/ATS/SIS International Sepsis Definitions Conference. Crit Care Med. 2003;31(4):1250-6. https://doi.org/10. 1097/01.Ccm.0000050454.01978.3b.

9. Mierzchała-Pasierb M, Lipińska-Gediga M. Sepsis diagnosis and monitoring-procalcitonin as standard, but what next? Anaesthesiol Intensive Therapy. 2019;51(4):299-305. https://doi.org/10.5114/ ait.2019.88104.

10. Pierrakos C, Vincent JL. Sepsis biomarkers: a review. Crit Care (London, England). 2010;14(1):R15. https://doi.org/10.1186/cc8872.

11. Giannakopoulos K, Hoffmann U, Ansari U, Bertsch T, Borggrefe M, Akin I, et al. The use of biomarkers in sepsis: a systematic review. Curr Pharm Biotechnol. 2017;18(6):499-507. https://doi.org/ $10.2174 / 1389201018666170601080111$.

12. $\mathrm{Xu} \mathrm{J,} \mathrm{Zhang} \mathrm{X}$, Pelayo R, Monestier M, Ammollo CT, Semeraro F, et al. Extracellular histones are major mediators of death in sepsis. Nat Med. 2009;15(11):1318-21. https://doi.org/10.1038/nm. 2053.

13. Tang D, Kang R, Coyne CB, Zeh HJ, Lotze MT. PAMPs and DAMPs: signal Os that spur autophagy and immunity. Immunol Rev. 2012;249(1):158-75. https://doi.org/10.1111/j.1600-065X.2012.01146.x.

14. Abrams ST, Zhang N, Manson J, Liu T, Dart C, Baluwa F, et al. Circulating histones are mediators of trauma-associated lung injury. Am J Respir Crit Care Med. 2013;187(2):160-9. https://doi.org/10. 1164/rccm.201206-1037OC.

15. Semeraro F, Ammollo CT, Morrissey JH, Dale GL, Friese P, Esmon NL, et al. Extracellular histones promote thrombin generation through platelet-dependent mechanisms: involvement of platelet TLR2 and TLR4. Blood. 2011;118(7):1952-61. https://doi. org/10.1182/blood-2011-03-343061.

16. Gould TJ, Lysov Z, Swystun LL, Dwivedi DJ, Zarychanski R, Fox-Robichaud AE, et al. Extracellular histones increase tissue factor activity and enhance thrombin generation by human blood monocytes. Shock (Augusta, Ga). 2016;46(6): 655-62. 0000000000000680.

17. Xu Z, Huang Y, Mao P, Zhang J, Li Y. Sepsis and ARDS: the dark side of histones. Mediators 
Inflamm. 2015;2015: 205054. https://doi.org/10. $1155 / 2015 / 205054$.

18. Ito T, Totoki T, Yokoyama Y, Yasuda T, Furubeppu $\mathrm{H}$, Yamada S, et al. Serum histone H3 levels and platelet counts are potential markers for coagulopathy with high risk of death in septic patients: a single-center observational study. J Intensive Care. 2019;7:63. https://doi.org/10.1186/s40560-0190420-2.

19. Wildhagen KC, Wiewel MA, Schultz MJ, Horn J, Schrijver R, Reutelingsperger CP, et al. Extracellular histone H3 levels are inversely correlated with antithrombin levels and platelet counts and are associated with mortality in sepsis patients. Thromb Res. 2015;136(3):542-7. https://doi.org/10. 1016/j.thromres.2015.06.035.

20. Osman M, Wendt-Nordahl G, Heger K, Michel MS, Alken P, Knoll T. Percutaneous nephrolithotomy with ultrasonography-guided renal access: experience from over 300 cases. BJU Int. 2005;96(6): 875-8. https://doi.org/10.1111/j.1464-410X.2005. 05749.x.

21. Michel MS, Trojan L, Rassweiler JJ. Complications in percutaneous nephrolithotomy. Eur Urol. 2007;51(4):899-906. https://doi.org/10.1016/j. eururo.2006.10.020 (discussion 906).

22. Gao X, Lu C, Xie F, Li L, Liu M, Fang Z, et al. Risk factors for sepsis in patients with struvite stones following percutaneous nephrolithotomy. World J Urol. 2020;38(1):219-29. https://doi.org/10.1007/ s00345-019-02748-0.

23. Wagenius $\mathrm{M}$, Borglin J, Popiolek M, Forsvall A, Stranne J, Linder A. Percutaneous nephrolithotomy and modern aspects of complications and antibiotic treatment. Scand J Urol. 2020;54(2):162-70. https:// doi.org/10.1080/21681805.2020.1740316.

24. Bansal SS, Pawar PW, Sawant AS, Tamhankar AS, Patil SR, Kasat GV. Predictive factors for fever and sepsis following percutaneous nephrolithotomy: a review of 580 patients. Urol Ann. 2017;9(3):230-3. https://doi.org/10.4103/ua.Ua_166_16.

25. McAleer IM, Kaplan GW, Bradley JS, Carroll SF, Griffith DP. Endotoxin content in renal calculi. J Urol. 2003;169(5):1813-4. https://doi.org/10. 1097/01.ju.0000061965.51478.79.

26. Troxel SA, Low RK. Renal intrapelvic pressure during percutaneous nephrolithotomy and its correlation with the development of postoperative fever. J Urol. 2002;168(4 Pt 1):1348-51. https://doi.org/ 10.1097/01.ju.0000030996.64339.f1.

27. Semeraro N, Ammollo CT, Semeraro F, Colucci M. Sepsis, thrombosis and organ dysfunction. Thromb
Res. 2012;129(3):290-5. https://doi.org/10.1016/j. thromres.2011.10.013.

28. Kono H, Rock KL. How dying cells alert the immune system to danger. Nat Rev Immunol. 2008;8(4): 279-89. https://doi.org/10.1038/nri2215.

29. Denning N-L, Aziz M, Gurien SD, Wang P. DAMPs and NETs in sepsis. Front Immunol. 2019. https:// doi.org/10.3389/fimmu.2019.02536.

30. Saffarzadeh M, Juenemann C, Queisser MA, Lochnit G, Barreto G, Galuska SP, et al. Neutrophil extracellular traps directly induce epithelial and endothelial cell death: a predominant role of histones. PLoS ONE. 2012;7(2): e32366. https://doi. org/10.1371/journal.pone.0032366.

31. Allam R, Kumar SV, Darisipudi MN, Anders HJ. Extracellular histones in tissue injury and inflammation. J Mol Med (Berl). 2014;92(5):465-72. https://doi.org/10.1007/s00109-014-1148-z.

32. Ekaney ML, Otto GP, Sossdorf M, Sponholz C, Boehringer $\mathrm{M}$, Loesche $\mathrm{W}$, et al. Impact of plasma histones in human sepsis and their contribution to cellular injury and inflammation. Crit Care (London, England). 2014;18(5):543. https://doi.org/10. 1186/s13054-014-0543-8.

33. Carestia A, Rivadeneyra L, Romaniuk MA, Fondevila C, Negrotto S, Schattner M. Functional responses and molecular mechanisms involved in histonemediated platelet activation. Thromb Haemost. 2013;110(5):1035-45. https://doi.org/10.1160/ th13-02-0174.

34. Meegan JE, Yang X, Beard RS Jr, Jannaway M, Chatterjee V, Taylor-Clark TE, et al. Citrullinated histone 3 causes endothelial barrier dysfunction. Biochem Biophys Res Commun. 2018;503(3): 1498-502. https://doi.org/10.1016/j.bbrc.2018.07. 069.

35. Friggeri A, Banerjee S, Xie N, Cui H, De Freitas A, Zerfaoui $M$, et al. Extracellular histones inhibit efferocytosis. Mol Med (Cambridge, Mass). 2012;18(1):825-33. https://doi.org/10.2119/ molmed.2012.00005.

36. Lu N, Jiang L, Zhu B, Yang D, Zheng R, Shao J, et al. Prediction value of plasma histone in prognosis of sepsis patients. Zhonghua wei zhong bing ji jiu yi xue. 2019;31(6):674-9. https://doi.org/10.3760/ cma.j.issn.2095-4352.2019.06.003.

37. Beltrán-García J, Manclús JJ, García-López EM, Carbonell N, Ferreres J, Rodríguez-Gimillo M, et al. Comparative analysis of chromatin-delivered biomarkers in the monitoring of sepsis and septic shock: a pilot study. Int J Mol Sci. 2021. https://doi. org/10.3390/ijms22189935. 